\title{
A prospective, randomized comparison of 3 contemporary bioprosthetic aortic valves: Should hemodynamic performance influence device selection?
}

\author{
Rakesh M. Suri, MD, DPhil, ${ }^{\mathrm{a}}$ Hector I. Michelena, MD, ${ }^{\mathrm{b}}$ Harold M. Burkhart, MD, ${ }^{\mathrm{a}}$ Kevin L. Greason, MD, ${ }^{\mathrm{a}}$ \\ Richard C. Daly, MD, ${ }^{a}$ Joseph A. Dearani, MD, ${ }^{a}$ Soon J. Park, MD, ${ }^{a}$ Lyle D. Joyce, MD, ${ }^{a}$ \\ John M. Stulak, MD, ${ }^{\text {a }}$ Thoralf M. Sundt III, MD, ${ }^{\mathrm{d}}$ Zhuo Li, MS, ${ }^{\mathrm{c}}$ and Hartzell V. Schaff, MD ${ }^{\mathrm{a}}$
}

Objective: Latest generation biologic aortic valve prostheses were designed to improve hemodynamic performance. We sought to determine whether there are clinically important early differences among these devices.

Methods: Three hundred adults with severe aortic valve stenosis undergoing aortic valve replacement were randomized to receive the Edwards Magna, Sorin Mitroflow, or St. Jude Epic bioprostheses $(\mathrm{n}=100$, $\mathrm{n}=101, \mathrm{n}=99$, respectively). Early hemodynamic performance was studied by echocardiography.

Results: Mean patient age was $76 \pm 8$ years and there were 203 men $(68 \%)$. There were no significant differences in baseline characteristics among implant groups. Early mortality was $1.7 \%$, and there were no differences in early adverse events. Postoperative echocardiography showed small but statistically significant differences overall between the Magna, Mitroflow, and Epic valves in mean gradient $(14.2 \mathrm{~mm} \mathrm{Hg}, 16.3 \mathrm{~mm} \mathrm{Hg}, 16.5$ $\mathrm{mm} \mathrm{Hg}$, respectively; $P=.011)$, aortic valve area $\left(2.05 \mathrm{~cm}^{2}, 1.88 \mathrm{~cm}^{2}, 1.86 \mathrm{~cm}^{2}\right.$, respectively; $\left.P=.012\right)$, and indexed aortic valve area $\left(1.05 \mathrm{~cm}^{2} / \mathrm{m}^{2}, 0.97 \mathrm{~cm}^{2} / \mathrm{m}^{2}, 0.95 \mathrm{~cm}^{2} / \mathrm{m}^{2}\right.$, respectively; $\left.P=.012\right)$. Prosthetic performance was similar among all with a small $(\leq 21 \mathrm{~mm})$ aortic annulus. Patients who received the Magna device with a 23-mm annulus had slightly greater indexed aortic valve area; those with $>23 \mathrm{~mm}$ had a slightly lower transprosthetic gradient. Analogous trends were found when data were stratified by either commercial implant size or echocardiography-determined aortic annulus size. Severe patient-prosthesis mismatch was infrequent overall and was similarly low among devices ( $P$ value not significant).

Conclusions: This prospective, randomized comparison reveals that there are small but consistent early postoperative hemodynamic differences among current third-generation porcine and pericardial aortic valve prostheses. The 3 valves studied performed equally well in patients with a small $(\leq 21 \mathrm{~mm})$ aortic annulus. The Magna valve had a slightly lower mean gradient in those with larger annular size $(>23 \mathrm{~mm})$. Longitudinal follow-up of these randomized cohorts is essential to determine late clinical implications of these early postoperative findings. (J Thorac Cardiovasc Surg 2012;144:1387-98)

Palliation of severe calcific aortic valve stenosis (AS) via prosthetic valve replacement may impose additional disease burden in the form of excess residual transprosthetic gradient in addition to either structural valve deterioration with biologic devices or mandatory anticoagulation for mechanical valve substitutes. Commercial heart valve companies have sought to promote the utilization of third-generation bioprosthetic valves by promising diminished residual gradients and improved late durability. ${ }^{1-8}$ Several factors

\footnotetext{
From the Divisions of Cardiovascular Surgery, ${ }^{\mathrm{a}}$ Cardiovascular Diseases, ${ }^{\mathrm{b}}$ and Biomedical Statistics and Informatics, ${ }^{\mathrm{c}}$ Mayo Clinic, Rochester, Minn; and the Division of Cardiac Surgery, ${ }^{\mathrm{d}}$ Massachusetts General Hospital, Boston, Mass. Disclosures: Authors have nothing to disclose with regard to commercial support. Read at the 92nd Annual Meeting of The American Association for Thoracic Surgery, San Francisco, California, April 28-May 2, 2012.

Received for publication April 29, 2012; revisions received June 11, 2012; accepted for publication July 25, 2012.

Address for reprints: Rakesh M. Suri, MD, DPhil, Division of Cardiovascular Surgery, Mayo Clinic, 200 First St SW, Rochester, MN 55905 (E-mail: suri. rakesh@mayo.edu)

$0022-5223 / \$ 36.00$

Copyright (c) 2012 by The American Association for Thoracic Surgery

http://dx.doi.org/10.1016/j.jtcvs.2012.07.105
}

complicate the comparison of early hemodynamic performance among devices, including heterogeneity of commercial valve sizers, differing prosthetic leaflet tissue types (bovine vs porcine), ${ }^{9}$ varied leaflet preservation/anticalcification treatment, and the disparate study designs within which devices are compared.

Despite commercial claims of differing hemodynamic performance and clinical outcomes, third-generation biologic heart valve prostheses have seldom been compared in prospective, randomized trials. We therefore sought to study the early clinical and hemodynamic differences between 3 commonly used biologic aortic valve substitutes-the St. Jude Epic porcine (St. Jude Medical, Minneapolis, Minn), the Sorin Mitroflow bovine pericardial valve (Sorin Group, Saluggia, Italy), or the Edwards Magna (Edwards LifeSciences, Irvine, Calif) aortic valvesfollowing randomized assignment to 300 patients with severe AS undergoing aortic valve replacement (AVR).

\section{METHODS}

The study was approved by the Mayo Clinic Institutional Review Board. 


\author{
Abbreviations and Acronyms \\ AS = aortic valve stenosis \\ $\mathrm{AVA}=$ aortic valve area \\ $\mathrm{AVAi}=$ indexed AVA \\ AVR $=$ aortic valve replacement \\ BSA = body surface area \\ $\mathrm{EF} \quad=$ ejection fraction \\ $\mathrm{LV}=$ left ventricular \\ LVEF $=$ left ventricular ejection fraction \\ LVOT $=$ left ventricular outflow tract \\ PPM $=$ patient-prosthesis mismatch
}

\section{Patients}

From August 13, 2009, to November 9, 2011, 300 consecutive patients with severe AS who were referred for biologic AVR were considered for enrollment. Included were those with a history of healed aortic valve endocarditis and patients undergoing concomitant procedures such as coronary artery bypass grafting or valve repair. Patients with the following characteristics were not included in the study: $<18$ years of age, emergency surgery, preexisting prosthetic heart valve in any location, previous aortic valve procedure or aortic root replacement, concomitant replacement of valves other than the aortic, active endocarditis, or severe aortic insufficiency (AV regurgitant volume $>60 \mathrm{~mL} /$ beat). All patients provided informed consent and expressed a willingness to follow the requirements of the protocol.

\section{Aortic Valve Replacement}

Randomization numbers were generated by the statistician using the SAS program (SAS9.2; SAS Institute, Inc, Cary, NC), printed on cards, and placed inside sealed envelopes. Patients underwent standard cardiopulmonary bypass and cold-blood cardioplegic arrest. After aortotomy, excision of the native aortic valve cusps, and debridement of the aortic annulus, the native aortic annulus was measured using a calibrated universal sizer $(19,21,23,25,27$, and $29 \mathrm{~mm})$. A decision was then made by the operative surgeon whether to enlarge the aortic annulus at that point in the operation prior to randomization. If the annulus was patch enlarged, the neo-annular size was remeasured with the universal sizer. The randomization envelope was then opened and the surgeon was instructed regarding the valve type to be implanted: the Edwards Magna, the St. Jude Epic, or the Sorin Mitroflow. Next, the annulus was measured using proprietary aortic sizers supplied by the valve manufacturers according to their recommended techniques. Surgeons assessed the geospatial relationship of the propriety replica aortic valve sizer within the aortic root and made a decision regarding whether a smaller prosthesis would need to be placed (ie, downsized) to facilitate implantation. Every effort was made by the surgeon to implant the largest possible aortic valve prosthesis. Aortic valve devices were implanted using noneverting pledgeted stitches. Patch closure of the aortic root was performed as indicated by the technical inability to close the aortotomy around strut posts of the implanted device.

The St. Jude Epic Supra porcine bioprosthesis is a triple-composite bioprosthetic heart valve manufactured from select porcine aortic valve cusps. The cusps are matched for leaflet coaptation. After fixation, the tissue is mounted on a polyester-covered flexible copolymer stent and was used in sizes 19 through 27 for the study. The Edwards Magna tissue valve is comprised of glutaraldehyde-fixed bovine pericardium mounted on a 3-pronged polyester Elgiloy stent and is available in sizes 19 through 27. The Sorin Mitroflow stented pericardial bioprosthesis is constructed from glutaraldehyde-fixed bovine pericardium sutured onto a polyester cloth-covered, flexible acetyl homopolymer stent. The pericardial tissue thickness is matched to the stent diameter and the valve is available in sizes 19 through 27.

\section{Echocardiography}

All patients underwent comprehensive 2-dimensional and Doppler transthoracic echocardiographic evaluation with state-of-the-art technology preoperatively and prior to hospital dismissal. Multiplane transesophageal echocardiography was used intraoperatively, and intraoperative data were reported whenever additional preoperative information was not available using transthoracic data. Left ventricular ejection fraction (LVEF) was assessed with 2-dimensional echocardiography by measuring the left ventricular (LV) short axis using a modification of the method of Quinones and colleagues ${ }^{10}$ or visual estimation. ${ }^{11}$ Pulsed and continuous-wave Doppler measurements were performed according to best practice, ${ }^{12}$ with a measurement average of 3 beats in sinus rhythm and 5 to 10 beats in atrial fibrillation. With appropriate gain and processing adjustments, the left ventricular outflow tract (LVOT) diameter was measured in the parasternal long axis within a midsystolic zoomed freeze frame, inner edge to inner edge from where the anterior cusp meets the ventricular anteroseptum to the point where the posterior cusp meets the anterior mitral leaflet for native aortic valves, and from the outer edge of the anterior sewing ring to the outer edge of the posterior sewing ring for prosthetic aortic valves. The LVOT time-velocity integral was obtained after proper cursor alignment to the aortic flow, in the apical 3-chamber view, with a sample volume placed above the color-flow prestenotic acceleration aliasing zone (0.5-1 $\mathrm{cm}$ above the aortic annulus) to record a laminar Doppler envelope without spectral dispersion. ${ }^{13}$ The transvalvular time-velocity integral, peak transvalvular velocity, and mean transvalvular gradient were determined by a systematic search of the highest values in all possible windows (apical, subcostal, supraclavicular, suprasternal, and right parasternal) with the nonimaging continuous-wave probe. The aortic mean gradient, peak velocity, and aortic valve time-velocity integral were calculated automatically by echocardiographic software. Aortic valve area (AVA) was calculated automatically by the continuity equation as $\mathrm{AVA}=\mathrm{LVOT} d 2 \times 0.785 \times$ LVOT $-\mathrm{TVI} / \mathrm{AV}-\mathrm{TVI}$, where TVI is transvalvular time-velocity integral and AV is aortic valve; and AVA indexed (AVAi) as AVAi $=$ AVA/BSA, where BSA is body surface area. Valvular regurgitation was assessed according to state-of-the-art guidelines. ${ }^{14}$ Stroke work loss was expressed as a percentage and was obtained using the equation $100 \times(\Delta \mathrm{P} / \Delta \mathrm{P} \times \mathrm{SPB})$, where $\mathrm{SPB}$ is systolic blood pressure. ${ }^{15}$ Patient-prosthesis mismatch (PPM) ${ }^{16}$ was calculated according to Rahimtoola $^{17-19}$ as AVA/BSA $<0.6 \mathrm{~cm}^{2} / \mathrm{m}^{2}$. One cardiologist specializing in echocardiographic imaging (H.I.M.) supervised the uniform collection and reporting of echocardiographic data in this study.

\section{Statistical Methods}

The sample size calculations were based on 2-sample $t$ test. The following formula was used to determine the sample size for detecting the difference of $\delta=\mu_{c}-\mu_{i}$ between any 2 of the 3 groups, where $\mathrm{N}$ is the sample size for each group and $\sigma$ is the common standard deviation:

$$
2 N=\frac{4\left(Z_{\alpha}+Z_{\beta}\right)^{2} \sigma^{2}}{\delta^{2}}
$$

Based on an overall significance level of 0.05 , with Bonferroni adjustment for multiple comparisons, a power of $80 \%$, and a common standard deviation of 5 , we estimated that we would require approximately 68 patients per group to detect a difference of 2.8 in mean predischarge gradient between any 2 of the 3 groups. To take into consideration possible dropouts, 100 patients were enrolled in each group.

Descriptive statistics for categorical variables are reported as frequency and percentage whereas continuous variables are reported as mean (standard deviation) or median (range) as appropriate. Categorical variables were compared between groups using the $\chi^{2}$ test or Fisher 
TABLE 1. Baseline characteristics

\begin{tabular}{|c|c|c|c|c|}
\hline Characteristic & Epic $(\mathbf{n}=99)$ & $\operatorname{Magna}(\mathbf{n}=100)$ & Mitroflow $(\mathbf{n}=101)$ & $P$ value \\
\hline Age & $75.93 \pm 8.12(77.00)$ & $75.50 \pm 7.39(76.50)$ & $75.59 \pm 8.68(77.00)$ & .874 \\
\hline Body mass index & $30.18 \pm 5.72(29.45)$ & $30.07 \pm 6.21(29.95)$ & $30.79 \pm 6.28(30.30)$ & .729 \\
\hline Coronary artery disease $>50 \%$ in $\geq 1$ vessel & $35(35)$ & $33(33)$ & $39(39)$ & .706 \\
\hline Cardiac index, $\mathrm{L} / \mathrm{min} / \mathrm{m}^{2}$ & $3.16 \pm 0.63(3.03)$ & $3.26 \pm 0.60(3.27)$ & $3.18 \pm 0.68(3.05)$ & .471 \\
\hline Congestive heart failure & $6(6)$ & $6(6)$ & $6(6)$ & .999 \\
\hline Chronic kidney failure & $4(4)$ & $4(4)$ & $1(1)$ & .348 \\
\hline Chronic obstructive pulmonary disease & $7(7)$ & $16(16)$ & $9(9)$ & .098 \\
\hline Diabetes & $21(21)$ & $20(20)$ & $26(26)$ & .588 \\
\hline \multicolumn{5}{|l|}{ Etiology of aortic valve disease } \\
\hline Congenital bicuspid & $15(15)$ & $22(22)$ & $19(19)$ & .463 \\
\hline Degenerative senile calcific & $79(80)$ & $76(76)$ & $77(76)$ & .774 \\
\hline Rheumatic/other & $5(5)$ & $2(2)$ & $5(5)$ & .472 \\
\hline Male & $73(74)$ & $64(64)$ & $66(65)$ & .282 \\
\hline Myocardial infarction & $11(11)$ & $10(10)$ & $8(8)$ & .740 \\
\hline NYHA class 3-4 & $43(48)$ & $45(48)$ & $35(39)$ & .375 \\
\hline Prior cardiovascular surgery & $5(5)$ & $7(7)$ & $5(5)$ & .779 \\
\hline Renal failure (dialysis dependent) & $2(2)$ & $1(1)$ & $0(0)$ & .357 \\
\hline \multicolumn{5}{|l|}{ Rhythm } \\
\hline Atrial fibrillation/flutter & $9(9)$ & $6(6)$ & $4(4)$ & .325 \\
\hline Normal sinus & $84(85)$ & $86(86)$ & $89(88)$ & .792 \\
\hline Other & $6(6)$ & $8(8)$ & $8(8)$ & .838 \\
\hline Smoking & $1(1)$ & $2(2)$ & $2(2)$ & .823 \\
\hline Systemic hypertension & $72(72)$ & $65(65)$ & $71(71)$ & .481 \\
\hline $\begin{array}{l}\text { Transient ischemic attack/cerebrovascular } \\
\text { accident }(\%)\end{array}$ & $7(7)$ & $12(12)$ & $4(4)$ & .097 \\
\hline \multicolumn{5}{|l|}{ Echocardiogram } \\
\hline Aorta size & $(\mathrm{n}=69) 36.97 \pm 4.34(36.00)$ & $(\mathrm{n}=61) 36.54 \pm 4.15(36.00)$ & $(\mathrm{n}=76) 35.75 \pm 3.63(35.00)$ & .156 \\
\hline Aortic valve area, $\mathrm{cm}^{2}$ & $0.91 \pm 0.21(0.91)$ & $0.88 \pm 0.20(0.88)$ & $0.87 \pm 0.19(0.87)$ & .404 \\
\hline Aortic valve area index, $\mathrm{cm}^{2} / \mathrm{m}^{2}$ & $0.46 \pm 0.11(0.44)$ & $0.45 \pm 0.10(0.44)$ & $0.45 \pm 0.09(0.44)$ & .800 \\
\hline Ejection fraction $(\%)$ & $60.02 \pm 11.12(63.00)$ & $60.51 \pm 11.20(63.00)$ & $61.75 \pm 11.31(65.00)$ & .233 \\
\hline Left ventricular outflow tract, $\mathrm{cm}$ & $2.29 \pm 0.20(2.30)$ & $2.26 \pm 0.19(2.20)$ & $2.25 \pm 0.19(2.20)$ & .334 \\
\hline Mean gradient, $\mathrm{mm} \mathrm{Hg}$ & $48.50 \pm 14.14(45.00)$ & $50.85 \pm 14.44(50.00)$ & $49.13 \pm 14.67(46.00)$ & .386 \\
\hline Peak velocity, $\mathrm{m} / \mathrm{s}$ & $4.44 \pm 0.64(4.40)$ & $4.47 \pm 0.69(4.50)$ & $4.44 \pm 0.69(4.40)$ & .834 \\
\hline
\end{tabular}

Continuous variables are summarized as mean \pm standard deviation (median) and categorical variables are summarized as $n$ (percentage). NYHA, New York Heart Association.

exact test, and continuous variables were analyzed using 1-way analysis of variance or the Kruskal-Wallis test when appropriate. All statistical tests were 2 -sided, with the alpha level set at .05 for statistical significance.

\section{Statement of Responsibility}

The authors had full access to the data and take responsibility for its integrity. All authors have read and agree to the manuscript as written.

\section{RESULTS \\ Preoperative}

Baseline characteristics for all 3 groups are reported in Table 1. Other than heart rhythm, there were no significant differences in either clinical or echocardiographic variables among implant groups prior to AVR. Just less than half of the patients had class III to IV symptoms preoperatively, and $77 \%(\mathrm{n}=232)$ underwent AVR to relieve severe senile calcific AS. Mean preoperative EF was $60.8 \%$, average mean transaortic gradient was $49.5 \mathrm{~mm} \mathrm{Hg}$, and mean AVA was $0.88 \mathrm{~cm}^{2}$. Prior cardiac surgery had been performed in $6 \%$ of patients $(\mathrm{n}=17)$, with similar frequencies among groups $(P=.779)$. The Epic valve was implanted in 99 patients, the Magna in 100 patients, and the Mitroflow in 101 patients.

\section{Operative}

Concomitant procedures were performed in $52 \%$ of patients $(\mathrm{n}=156)$ and include, broadly, aortic annular enlargement $(\mathrm{n}=13,4 \%)$, septal myectomy $(\mathrm{n}=17$, $6 \%)$, coronary bypass grafting $(n=111,37 \%)$, mitral valve repair $(\mathrm{n}=8,2.7 \%)$, tricuspid valve repair $(\mathrm{n}=4,1 \%)$, ascending aortic replacement $(\mathrm{n}=10$, $3 \%)$, aortic root replacement $(\mathrm{n}=2,1 \%)$, and ablation for atrial fibrillation $(\mathrm{n}=13,4 \%)$. There were no other important operative differences among groups (Table 2). Median crossclamp time was 45 minutes for those having isolated AVR and was 57 minutes overall, with no significant differences among valves $(P=.39$ and $P=.70$, respectively). Early adverse events were infrequent, with 
TABLE 2. Perioperative outcomes

\begin{tabular}{|c|c|c|c|c|}
\hline Outcome & Epic $(n=99)$ & Magna $(n=100)$ & Mitroflow $(n=101)$ & $P$ value \\
\hline Bypass time, min & $86.64 \pm 71.70(70.00)$ & $84.20 \pm 42.51(75.50)$ & $82.33 \pm 43.12(71.00)$ & .803 \\
\hline $\begin{array}{l}\text { Isolated aortic valve replacement } \\
\text { bypass time, } \min \end{array}$ & $(\mathrm{n}=49) 57.78 \pm 27.98(53.00)$ & $(\mathrm{n}=46) 57.48 \pm 21.59(52.50)$ & $(\mathrm{n}=49) 62.45 \pm 22.85(60.00)$ & .306 \\
\hline Crossclamp time, $\min$ & $63.03 \pm 30.65(57.00)$ & $66.13 \pm 30.95(60.00)$ & $64.74 \pm 30.88(52.00)$ & .704 \\
\hline $\begin{array}{l}\text { Isolated aortic valve replacement } \\
\text { crossclamp time, min }\end{array}$ & $(\mathrm{n}=49) 46.45 \pm 17.90(43.00)$ & $(\mathrm{n}=46) 54.17 \pm 16.31(42.00)$ & $(\mathrm{n}=49) 50.84 \pm 17.54(48.00)$ & .189 \\
\hline Concomitant procedure & $50(51)$ & $54(54)$ & $52(51)$ & .878 \\
\hline Aortic annulus enlargement & $5(5)$ & $4(4)$ & $4(4)$ & .912 \\
\hline $\begin{array}{l}\text { Patch aortic root closure (without } \\
\text { annular enlargement) }\end{array}$ & $7(7)$ & $11(11)$ & $8(8)$ & .584 \\
\hline Septal myectomy & $4(4)$ & $7(7)$ & $6(6)$ & .658 \\
\hline Early mortality* (\%) & $2(2)$ & $1(1)$ & $2(2)$ & .816 \\
\hline Hospital stay, day & $6.47 \pm 3.50(5.00)$ & $6.37 \pm 3.76(5.50)$ & $6.54 \pm 3.80(6.00)$ & .873 \\
\hline Reoperation for bleeding & $1(1)$ & $3(3)$ & $0(0)$ & .169 \\
\hline $\begin{array}{l}\text { Transient ischemic attack/ } \\
\text { cerebrovascular accident }(\%)\end{array}$ & $1(1)$ & $0(0)$ & $3(3)$ & .175 \\
\hline
\end{tabular}

4 patients $(1.3 \%)$ having a stroke/transischemic attack, 4 patients $(1.3 \%)$ requiring reoperation for bleeding. Five patients died $(1.7 \%)$ in the hospital or within 30 days of surgery.

\section{Postoperative}

Predismissal echocardiograms were performed at a median of 4 days after surgery (Table 3). Overall EF was similar among groups (Table $3, P=.070$ ), as was cardiac index $(P=.416)$. Overall mean transprosthetic gradient was slightly lower for Magna than for Epic $(P=.023)$ and Mitroflow $(P=.040)$; however, there was no difference between Epic and Mitroflow $(P=.972)$. Peak velocity was lower for Magna than for Epic $(P=.005)$ and Mitroflow $(P=.039)$; however, there was no difference between Epic and Mitroflow $(P=.748)$. AVA was slightly higher for Magna than for Epic $(P=.023)$ and Mitroflow $(P=.040)$; however, there was no difference between Epic and Mitroflow $(P=.972)$. AVAi was slightly higher for Magna than Epic $(P=.032)$, but Magna and Mitroflow were similar $(P=.097)$ as were Epic and Mitroflow $(P=.868)$. Stroke work loss was lowest for the Magna compared with that of Epic $(P=.008)$, and Mitroflow $(P=.009)$; however, there was no difference between Epic and Mitroflow $(P=.997)$.
When patients were divided into 3 similar-size groups for comparison (Figure 1 and Appendix 1), the following cohorts of commercially labeled valve size were obtained: nos. 19 and $21(\mathrm{n}=100)$, no. $23(\mathrm{n}=94)$, and nos. 25 and $27(\mathrm{n}=106)$. There were no significant differences in mean gradient, AVA, or AVAi among commercial valve types in those receiving the smallest device sizes (nos. 19 and 21). Hemodynamic differences emerged among those receiving a no. 23 valve when considering mean gradient $(P=.032)$, AVA $(P=.025)$, and AVAi $(P=.028)$. Among patients receiving a no. 25 or no. 27 Magna valve, the mean gradient was slightly lower $(P=.009)$ and the AVA was slightly higher $(P=.019)$.

When the stratification was based on actual annulus size as ascertained by calibrated universal sizer measurement at surgery (Figure 2 and Appendix 2), fewer differences among devices were identified. Most hemodynamic parameters were not significantly different among valve types aside from 2 categories: patients with an annulus size of $23 \mathrm{~mm}$ who received the Magna device had a slightly larger AVAi, and those $>23 \mathrm{~mm}$ had a slightly lower gradient. No other significant differences emerged among devices when stratified by actual annulus size. Echocardiographically measured aortic

TABLE 3. Dismissal echocardiogram

\begin{tabular}{|c|c|c|c|c|}
\hline Variable & Epic $(\mathbf{n}=99)$ & $\operatorname{Magna}(n=100)$ & Mitroflow $(\mathbf{n}=101)$ & $P$ value \\
\hline Mean gradient, $\mathrm{mm} \mathrm{Hg}$ & $16.51 \pm 6.42(16.00)$ & $14.23 \pm 5.48(14.00)$ & $16.31 \pm 6.09(16.00)$ & .011 \\
\hline Aortic valve area, $\mathrm{cm}^{2}$ & $1.86 \pm 0.48(1.77)$ & $2.05 \pm 0.54(1.98)$ & $1.88 \pm 0.52(1.82)$ & .012 \\
\hline Aortic valve area index, $\mathrm{cm}^{2} / \mathrm{m}^{2}$ & $0.95 \pm 0.25(0.90)$ & $1.05 \pm 0.25(1.00)$ & $0.97 \pm 0.27(0.96)$ & .012 \\
\hline Cardiac index, $\mathrm{L} / \mathrm{min} / \mathrm{m}^{2}$ & $3.34 \pm 0.65(3.33)$ & $3.50 \pm 0.73(3.36)$ & $3.44 \pm 0.70(3.41)$ & .416 \\
\hline Ejection fraction, $\%$ & $57.42 \pm 11.89(60.00)$ & $60.46 \pm 11.63(64.00)$ & $59.98 \pm 10.66(61.00)$ & .070 \\
\hline Peak velocity, $\mathrm{m} / \mathrm{s}$ & $2.72 \pm 0.48(2.70)$ & $2.49 \pm 0.45(2.50)$ & $2.66 \pm 0.50(2.70)$ & .005 \\
\hline Stroke work loss, $\%$ & $12.05 \pm 4.10(11.42)$ & $10.30 \pm 3.62(9.92)$ & $12.01 \pm 4.27(11.62)$ & .004 \\
\hline
\end{tabular}

Echocardiogram variables are summarized as mean \pm standard deviation (median). 

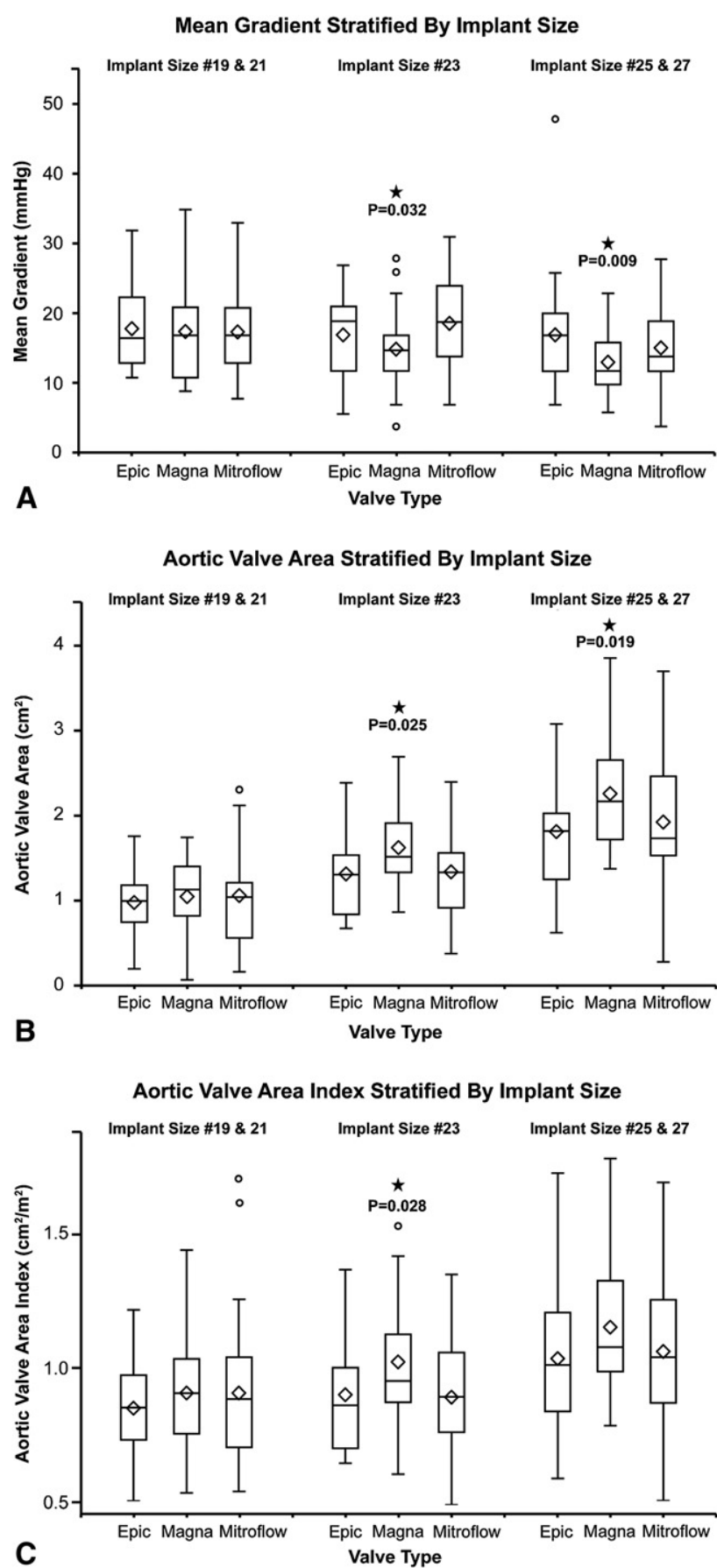

FIGURE 1. Early aortic valve prosthesis hemodynamics stratified by labeled valve size: nos. 19 and 21, no. 23, and nos. 25 and 27. A, Mean gradient was significantly lower in the Magna group for mid- (no. 23) to largesize (nos. 25 and 27) devices. B, Mean aortic valve area ( $\pm 95 \%$ confidence internal whiskers) was significantly higher in the Magna group for mid(no. 23) to large-size (nos. 25 and 27) devices. C, Mean indexed aortic valve area was significantly higher in the Magna group for only mid-size (no. 23) devices. Mean and median are represented by the squares and lines inside the box. Top and bottom box borders cover the middle 50\% of the data. Star indicates statistically significant comparison.
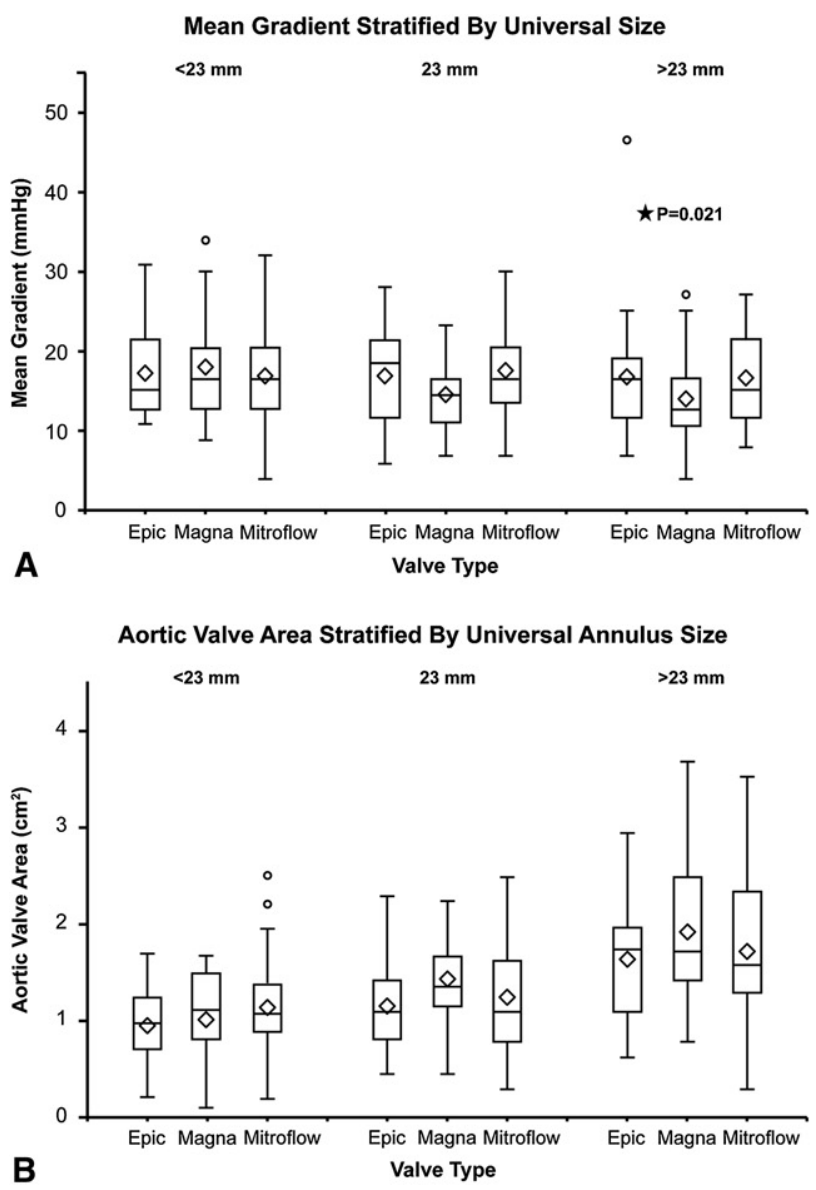

Aortic Valve Area Index Stratified By Universal Annulus Size

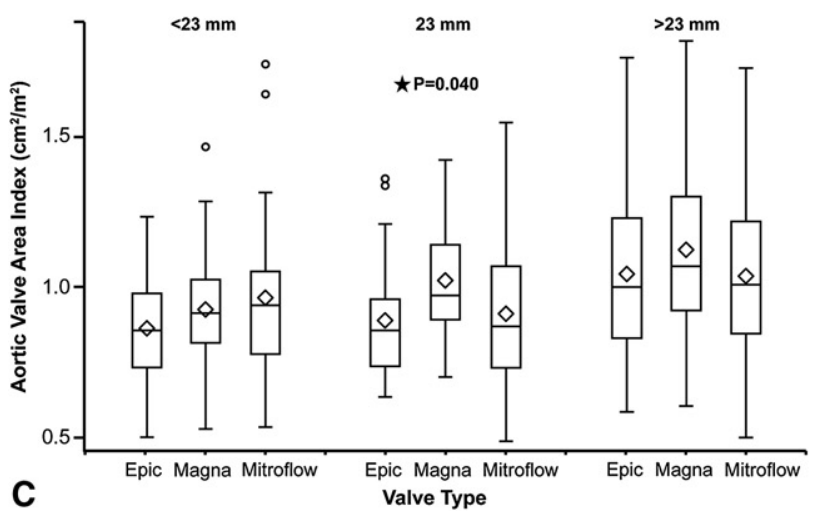

FIGURE 2. Early aortic valve prosthesis hemodynamics stratified by actual annular size (universal sizer) measured directly at surgery: $<23 \mathrm{~mm}$, $23 \mathrm{~mm}$, and $>23 \mathrm{~mm}$. A, Mean gradient was only lower in the Magna group in patients with a large aortic annulus $(>23 \mathrm{~mm})$. B, Mean aortic valve area was similar among all valves when stratified by each actual annulus size. $\mathrm{C}$, Mean indexed aortic valve area was only higher in the Magna group for patients with a midsize (23-mm) aortic annulus. Mean and median are represented by the squares and lines inside the box. Top and bottom box borders cover the middle $50 \%$ of the data. Star indicates statistically significant comparison. 


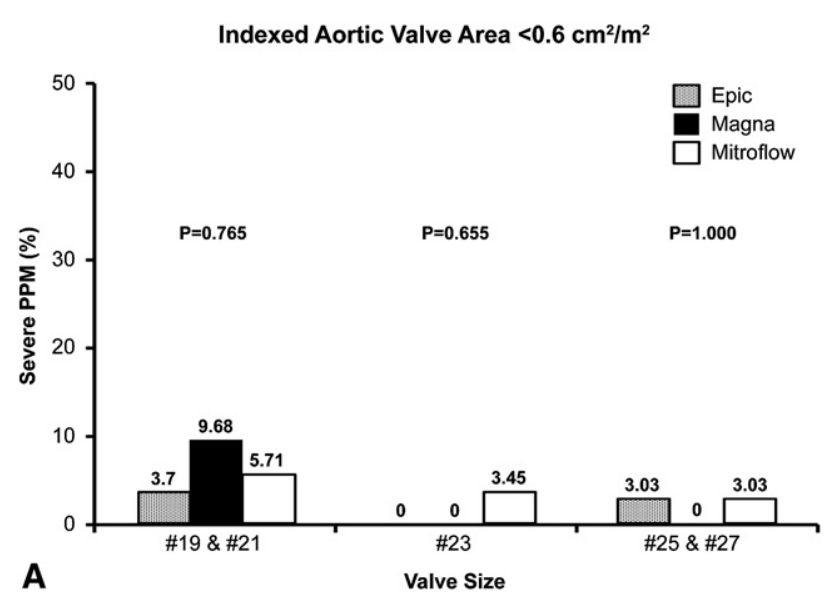

A

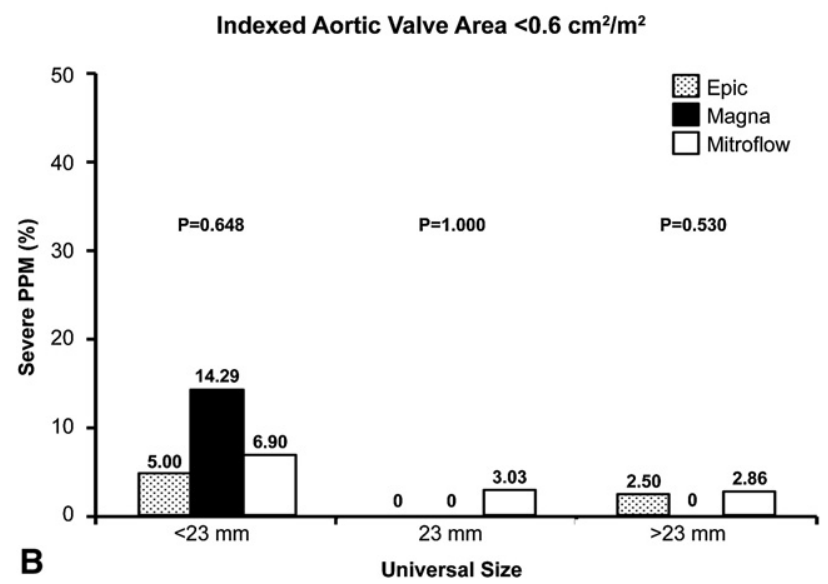

FIGURE 3. Incidence of severe patient-prosthesis mismatch (PPM; calculated as indexed aortic valve area $<0.6 \mathrm{~cm}^{2} / \mathrm{m}^{2}$ ). The frequency of severe PPM was statistically similar among groups when stratified by either labeled valve size (A) or actual annular size (universal sizer; B).

annulus (LVOT)-stratified data generally showed similar trends (Appendix 3).

The frequency of severe PPM was next calculated among devices based on labeled valve size (Figure $3, A$ ) and actual annulus size (Figure 3, B). Although patients who received the Magna device had a slightly higher frequency of severe PPM in small-labeled valve size $(3 / 29,10 \% ; P=.765)$ and small annulus size $<23 \mathrm{~mm}(3 / 23,14 \% ; P=.648)$, the differences were not significant. The incidence of prosthetic regurgitation grade $\geq$ mild was very low and similar among valve groups: Epic, $1 \%(\mathrm{n}=1)$; Magna, $2 \%(\mathrm{n}=2)$; and Mitroflow, $4 \%(\mathrm{n}=4 ; P=.37)$.

To understand more completely the relationship between the aortic annulus size and implanted valve size, Pearson correlation coefficients were calculated. Prosthesis dimensions reported by the 3 valve companies are shown in Table 4. Among all valve sizes, the actual annulus size and implant size correlated slightly better in the Epic $(P=.049)$ and Mitroflow $(P=.049)$ groups versus the Magna. The tendency was to implant a numerically
TABLE 4. Differences in commercial valve dimensions

\begin{tabular}{lcccc}
\hline Valve & $\begin{array}{c}\text { Internal } \\
\text { diameter, } \mathbf{m m}\end{array}$ & $\begin{array}{c}\text { Stent } \\
\text { diameter, } \mathbf{m m}\end{array}$ & $\begin{array}{c}\text { External } \\
\text { diameter, } \mathbf{m m}\end{array}$ & $\begin{array}{c}\text { Height, } \\
\text { mm }\end{array}$ \\
\hline No. 19 & & & & \\
Epic & 19 & 19 & 25 & 14 \\
Magna & 18 & 19 & 24 & 14 \\
Mitroflow & 15.4 & 18.6 & 21 & 11 \\
No. 21 & & & & \\
Epic & 21 & 21 & 28 & 15 \\
Magna & 20 & 21 & 26 & 15 \\
Mitroflow & 17.3 & 20.7 & 23 & 13 \\
No. 23 & & & & \\
Epic & 23 & 23 & 29 & 16 \\
Magna & 22 & 23 & 28 & 16 \\
Mitroflow & 19 & 22.7 & 26 & 14 \\
No. 25 & & & & \\
Epic & 25 & 25 & 31 & 17 \\
Magna & 24 & 25 & 30 & 17 \\
Mitroflow & 21 & 25.1 & 29 & 15 \\
No. 27 & & & & \\
Epic & 27 & 27 & 33 & 19 \\
Magna & 26 & 27 & 32 & 18 \\
Mitroflow & 22.9 & 27.3 & 31 & 16 \\
\hline & & & &
\end{tabular}

smaller (commercial size) Magna valve than the direct annular measurement would suggest (mean, $-0.71 \mathrm{~mm}$ ). The operative surgeon documented the need to downsize the implanted valve from the commercial size measured in 9 patients who received the Magna $(9 \%)$ versus 6 patients who received the Epic $(6 \%)$ and 4 patients who received the Mitroflow $(4 \% ; P=.338)$. Patch enlargement of the aortic annulus was performed in 5 patients who received the Epic (5\%), 4 patients who received the Magna $(4 \%)$, and 4 patients who received the Mitroflow $(4 \%$; $P=.91$ ). Isolated patch closure of the aortic root (without annular enlargement) was required in 11 patients receiving the Magna valve $(11 \%)$ versus 7 patients receiving the Epic valve $(7 \%)$ and 8 patients receiving the Mitroflow valve $(8 \% P=.58)$. Among patients with a small annulus having a direct annular measurement of $\leq 21 \mathrm{~mm}$, the universal size and implant size correlated best for the Mitroflow valve $(P=.045)$.

\section{DISCUSSION}

This is the first prospective, randomized clinical trial of patients with severe AS undergoing AVR with the Epic, Magna, or Mitroflow valves. Small but consistent differences were found. Valve performance was similar and statistically indistinguishable among those patients with a small $(\leq 21$ $\mathrm{mm}$ ) aortic annulus whereas the AVAi was slightly greater in patients with a 23-mm annulus who received the Magna. AVA and AVAi were comparable among all 3 valve types in patients with a larger annular dimension $(>23 \mathrm{~mm})$; however, slightly lower transprosthetic gradients were noted 
in the Magna group. Analogous trends were found when data were stratified either by commercially labeled valve size or echocardiographically determined aortic annulus size. The correlation between actual aortic annulus size and implanted commercial valve size was best in the Epic and Mitroflow groups.

The early postsurgical hemodynamic performance of the 3 valves studied was similar, in general, to previously reported values from retrospective reviews. ${ }^{2,5,8,20}$ Although the median implanted commercially labeled valve size was no. 23 in the current study, we divided patients for analysis into 3 equal groups to facilitate balanced statistical comparison among physiologically similar valve sizes. Mean transprosthetic gradients in the Epic group ranged between $17.1 \mathrm{~mm} \mathrm{Hg}$ (nos. 19 and 21) and $16.2 \mathrm{~mm} \mathrm{Hg}$ (nos. 25 and 27) in our study, which were slightly higher than those reported by Maitland associates ${ }^{8}$ but similar to Ruzicka and co-authors, ${ }^{20}$ both of whom detailed echocardiographic data accrued 6 months after implantation. AVA and AVAi were similar, however, among these reports and the current study. ${ }^{8,20}$ Mean transprosthetic gradients in the Magna group ranged between $16.6 \mathrm{~mm} \mathrm{Hg}$ (nos. 19 and 21) and 11.9 $\mathrm{mm} \mathrm{Hg}$ (nos. 25 and 27) in our series, which also were slightly higher than those reported by Botzenhardt and colleagues $^{2}$ (at hospital dismissal), whereas AVA and AVAi were again similar. Mitroflow valves showed similar trends, with mean gradients between $16.7 \mathrm{~mm} \mathrm{Hg}$ (nos. 19 and 21) and $14.5 \mathrm{~mm} \mathrm{Hg}$ (nos. 25 and 27) in our study, which were slightly higher than those reported by Jamieson and associates ${ }^{5}$ at a mean of 11 months after surgery, whereas AVA and AVAi in our study were, conversely, slightly greater. It is highly likely that heterogeneity in timing of hemodynamic assessments among our current and other studies accounts for many of these differences. Elevated circulating catecholamine levels along with increased stroke volume and anemia early postoperatively all play a role in altering flow-dependent parameters of prosthetic valve function such as mean gradient and peak velocity. ${ }^{13,21}$ Indeed, the postoperative increase in cardiac index (compared with preoperative) was significant overall in the current report $(+0.25 \pm 0.81$, $P<.001)$. It is reassuring that the postoperative cardiac index was similar among groups, thus facilitating comparison of mean gradients among prostheses. It is also notable that less flow-dependent measures of valve performance such as AVA and AVAi in our study were similar to prior published values in which echocardiographic examinations were typically performed well beyond the early postoperative period.

As others have shown, ${ }^{2,5,8,22}$ the comparison of hemodynamic differences among bioprostheses after correcting for actual annular size is important. It is interesting that the differences in AVAi among devices based on labeled valve size, actual (universal) annulus size, and echocardiography LVOT diameter were only significant in the intermediate group (ie, those receiving a no. 23 valve or having an annulus diameter of $23 \mathrm{~mm}$ ). Despite the fact that the maximal sewing cuff dimension reported by Edwards for the Magna valve is intermediate between the Epic and Mitroflow (Table 4), slightly more patients receiving the Magna valve required prosthesis downsizing and patch closure of the aortic root by the operative surgeon ( $P$ value not significant). This also supports our finding that the Pearson correlation coefficients of the relationship between annulus and implant sizes were weakest in the Magna group. Despite this, the Magna valve tended to perform slightly better in those with a medium to large annulus size. The Mitroflow had the smallest external sewing cuff footprint and correlated better with actual annular size, particularly in those with a small aortic annulus $(<21 \mathrm{~mm})$.

The prognostic impact of PPM has been debated widely. Historic estimates suggest that the incidence of PPM in stented aortic bioprostheses range from $20 \%$ to $70 \%{ }^{23,24}$ Varying degrees of PPM have been reported to influence clinical outcome by some, ${ }^{25-30}$ whereas others remain unconvinced. ${ }^{31-35}$ Differing methods used to calculate PPM likely contribute to the heterogeneity of published outcomes. ${ }^{36}$ A study by Connolly and colleagues ${ }^{37}$ from Mayo Clinic identified small aortic valve prosthesis as an independent predictor of poor early postsurgical survival in those with severe preoperative LV dysfunction $(\mathrm{EF}<35 \%) .{ }^{37}$ Specifically, Mohty and associates ${ }^{26}$ showed that severe PPM predicted increased late mortality in those $<70$ years old or with a body mass index $>30 \mathrm{~kg} / \mathrm{m}^{2}$, whereas moderate PPM was a risk factor for death in patients with an LVEF $<50 \%$. Urso and colleagues ${ }^{38}$ summarized the recent literature by recommending that severe mismatch may be deleterious in all patients whereas moderate mismatch might be a problem only in those with LV dysfunction. Our study suggests that the risk of severe PPM in patients receiving current-generation bioprosthetic aortic valves is extremely low and that differences among the 3 valves tested here are small. One clinical interpretation of the data is to suggest that patients with severe LV dysfunction and larger annular size may gain a small benefit from the slightly lower gradient offered by the Magna valve; however, randomized assessment of these 3 valves in patients with depressed preoperative LV function will be necessary before such a conclusion can be drawn. When considering less flow-dependent, and perhaps most objectively assessed parameters (ie, AVA and AVAi), the actual differences between the Magna and Mitroflow valves were small.

As David and coworkers ${ }^{39}$ suggest in their recent report, the debate regarding hemodynamic superiority and late durability of porcine versus bovine pericardial bioprosthesis persists largely as a result of the fact that 
different generations of valve have been compared in heterogeneous patient populations. Similar to the current study, Jamieson and colleagues ${ }^{40}$ compared the hemodynamic performance of the Carpentier-Edwards (Edwards LifeSciences) and Mosaic porcine aortic valves against the Carpentier-Edwards bovine pericardial device, finding that the mean gradient and AVAi were similar between the 2 valves, and thus concluded that there were no important hemodynamic differences between porcine and pericardial devices in the aortic position. In contrast, Wagner and associates $^{24}$ examined the hemodynamic performance of 3 bovine pericardial aortic valves (Sorin Soprano, Carpentier-Edwards Magna, and Carpentier-Edwards Perimount) and 1 porcine valve (Medtronic Mosaic), concluding that all 3 bovine pericardial valves showed lower transaortic gradients and larger "effective orifice fraction." A randomized study ${ }^{41}$ of 152 patients from Mayo Clinic compared the Mosaic porcine with the Carpentier-Edwards Perimount bovine pericardial valves in the aortic position and found that, although the mean gradient was higher and the AVAi lower in the Mosaic group, both cohorts showed similar regression of LV mass index at 1 year. Finally, regarding late durability, David and coworkers ${ }^{39}$ studied a large population of 1134 patients undergoing AVR with the Hancock II porcine bioprosthesis and reported that the freedom from structural valve deterioration at 20 years was $99.8 \%$ in patients $>70$ years. Even after accounting for these reports, there remains a paucity of comparative effectiveness data detailing the late durability of contemporary porcine versus bovine pericardial valves in the current era. Longitudinal follow-up of our randomized cohorts will thus hopefully facilitate further comment on this issue in the future.

The notion of various devices performing differently under specific physiologic circumstances has recently been proposed by Gerosa and colleagues ${ }^{42}$ who detailed hemodynamic comparisons using a pulse duplicator. Pericardial valves (Soprano, Magna, and Mitroflow) showed the lowest transvalvular gradients; the Mitroflow valve performed best at 5 to $7 \mathrm{~L} /$ minute with the lowest gradient, highest AVA, and lowest stroke work loss; whereas regurgitant volumes were highest for the Magna valve. A more recent study by the same group ${ }^{43}$ reported that the Magna and Mitroflow had significantly better hemodynamic performance in comparison with porcine valves, particularly with stroke volume-mediated increases in cardiac output. They speculated further that the porcine valves might perform better in elderly patients in whom the increase in cardiac output is heart rate mediated, presumably as a result of the "increased pliability" of the valve at higher cycle speeds. These findings may explain, in part, why the Epic valve performed similarly in the current study to pericardial valves in patients with a small aortic annulus size.

\section{Limitations}

Patients randomized to each of the 3 implant groups had similar preoperative characteristics, as typical of a randomized trial. Some of the measures of early hemodynamic performance (mean gradient and peak aortic velocity) of the devices studied in this report are undoubtedly influenced by factors known to affect flow-dependent indices; however, we examined those parameters understood to be more objective, such as AVA and AVAi. Continued follow-up at the 1- and 5-year time points are essential to more completely understanding the hemodynamic performance, durability, and clinical outcomes (including survival) of the randomized cohorts. Although echocardiograms were not performed in a core laboratory, cardiologists who contribute routinely to such studies analyzed images using rigorous Mayo Clinic protocols and standards. Last, the oversight of one cardiologist (Dr Michelena) in ensuring the homogeneous accrual and analysis of echocardiography data is reassuring.

\section{CONCLUSIONS}

This prospective, randomized comparison reveals that there are small but consistent hemodynamic trends among current third-generation porcine and pericardial aortic valve prostheses. The 3 valves studied performed equally well in patients with a small $(\leq 21 \mathrm{~mm})$ aortic annulus size. The Magna valve had a slightly lower mean gradient in those with a larger annulus size $(>23 \mathrm{~mm})$; however, flow-independent parameters such as AVA and AVAi were generally similar among groups. Longitudinal assessments of these randomized cohorts will be essential to determine late clinical implications of these early postoperative findings.

\section{References}

1. Borger MA, Nette AF, Maganti M, Feindel CM. Carpentier-Edwards Perimount Magna valve versus Medtronic Hancock II: a matched hemodynamic comparison. Ann Thorac Surg. 2007;83:2054-8.

2. Botzenhardt F, Eichinger WB, Guenzinger R, Bleiziffer S, Wagner I, Bauernschmitt R, et al. Hemodynamic performance and incidence of patientprosthesis mismatch of the complete supraannular Perimount Magna bioprosthesis in the aortic position. Thorac Cardiovasc Surg. 2005;53:226-30.

3. Dalmau MJ, González-Santos JM, Blázquez JA, Sastre JA, López-Rodríguez J, Bueno M, et al. Hemodynamic performance of the Medtronic Mosaic and Perimount Magna aortic bioprostheses: five-year results of a prospectively randomized study. Eur J Cardiothorac Surg. 2011;39:844-52.

4. Goetzenich A, Langebartels G, Christiansen S, Hatam N, Autschbach R, Dohmen G. Comparison of the Carpentier-Edwards Perimount and St. Jude Medical Epic bioprostheses for aortic valve replacement: a retrospective echocardiographic short-term study. J Cardiac Surg. 2009;24:260-4.

5. Jamieson WR, Forgie WR, Hayden RI, Langlois Y, Ling H, Stanford EA, et al. Hemodynamic performance of mitroflow aortic pericardial bioprosthesis: optimizing management for the small aortic annulus. Thorac Cardiovasc Surg. 2010;58:69-75.

6. Jamieson WR, Lewis CT, Sakwa MP, Cooley DA, Kshettry VR, Jones KW, et al. St Jude Medical Epic porcine bioprosthesis: results of the regulatory evaluation. J Thorac Cardiovasc Surg. 2011;141:1449-54.

7. Jamieson WRE, Koerfer R, Yankah CA, Zittermann A, Hayden RI, Ling H, et al. Mitroflow aortic pericardial bioprosthesis: clinical performance. Eur J Cardiothorac Surg. 2009;36:818-24. 
8. Maitland A, Hirsch GM, Pascoe EA. Hemodynamic performance of the St. Jude Medical Epic supra aortic stented valve. J Heart Valve Dis. 2011;20:327-31

9. Said SM, Ashikhmina E, Greason KL, Suri RM, Park SJ, Daly RC, et al. Do pericardial bioprostheses improve outcome of elderly patients undergoing aortic valve replacement? Ann Thorac Surg. 2012;93:1868-74; discussion, 1874-5.

10. Quinones MA, Waggoner AD, Reduto LA, Nelson JG, Young JB, Winters WL Jr, et al. A new, simplified and accurate method for determining ejection fraction with two-dimensional echocardiography. Circulation. 1981;64:744-53.

11. Rich S, Sheikh A, Gallastegui J, Kondos GT, Mason T, Lam W. Determination of left ventricular ejection fraction by visual estimation during real-time twodimensional echocardiography. Am Heart J. 1982;104:603-6.

12. Quinones MA, Otto CM, Stoddard M, Waggoner A, Zoghbi WA. Recommendations for quantification of Doppler echocardiography: a report from the Doppler Quantification Task Force of the Nomenclature and Standards Committee of the American Society of Echocardiography. J Am Soc Echocardiogr. 2002;15:167-84.

13. Baumgartner H, Hung J, Bermejo J, Chambers JB, Evangelista A, Griffin BP, et al. Echocardiographic assessment of valve stenosis: EAE/ASE recommendations for clinical practice. Eur J Echocardiogr. 2009;10:1-25.

14. Zoghbi WA, Enriquez-Sarano M, Foster E, Grayburn PA, Kraft CD, Levine RA, et al. Recommendations for evaluation of the severity of native valvular regurgitation with two-dimensional and Doppler echocardiography. J Am Soc Echocardiogr. 2003;16:777-802

15. Bermejo J, Odreman R, Feijoo J, Moreno MM, Gomez-Moreno P, GarciaFernandez MA. Clinical efficacy of Doppler-echocardiographic indices of aortic valve stenosis: a comparative test-based analysis of outcome. J Am Coll Cardiol. 2003;41:142-51.

16. Howell NJ, Keogh BE, Ray D, Bonser RS, Graham TR, Mascaro J, et al. Patient-prosthesis mismatch in patients with aortic stenosis undergoing isolated aortic valve replacement does not affect survival. Ann Thorac Surg. 2010;89: 60-4

17. Rahimtoola SH. Valve prosthesis-patient mismatch: an update. J Heart Valve Dis. 1998;7:207-10

18. Rahimtoola SH. Is severe valve prosthesis-patient mismatch (VP-PM) associated with a higher mortality? Eur J Cardiothorac Surg. 2006;30:1.

19. Rahimtoola SH. Choice of prosthetic heart valve in adults: an update. J Am Coll Cardiol. 2010;55:2413-26.

20. Ruzicka DJ, Hettich I, Hutter A, Bleiziffer S, Badiu CC, Bauernschmitt R, et al. The complete supraannular concept in vivo hemodynamics of bovine and porcine aortic bioprostheses. Circulation. 2009;120:S139-45.

21. Zoghbi WA, Chambers JB, Dumesnil JG, Foster E, Gottdiener JS, Grayburn PA, et al. Recommendations for evaluation of prosthetic valves with echocardiography and doppler ultrasound: a report from the American Society of Echocardiography's Guidelines and Standards Committee and the Task Force on Prosthetic Valves, developed in conjunction with the American College of Cardiology Cardiovascular Imaging Committee, Cardiac Imaging Committee of the American Heart Association, the European Association of Echocardiography, a registered branch of the European Society of Cardiology, the Japanese Society of Echocardiography and the Canadian Society of Echocardiography, endorsed by the American College of Cardiology Foundation, American Heart Association, European Association of Echocardiography, a registered branch of the European Society of Cardiology, the Japanese Society of Echocardiography, and Canadian Society of Echocardiography. J Am Soc Echocardiogr. 2009;22:975-1014. Quiz. 82-4.

22. Seitelberger R, Bialy J, Gottardi R, Seebacher G, Moidl R, Mittelböck M, et al. Relation between size of prosthesis and valve gradient: comparison of two aortic bioprosthesis. Eur J Cardiothorac Surg. 2004;25:358-63.

23. Pibarot P, Honos GN, Durand LG, Dumesnil JG. Substitution of left ventricular outflow tract diameter with prosthesis size is inadequate for calculation of the aortic prosthetic valve area by the continuity equation. J Am Soc Echocardiogr. 1995;8:511-7.

24. Wagner IM, Eichinger WB, Bleiziffer S, Botzenhardt F, Gebauer I, Guenzinger R, et al. Influence of completely supra-annular placement of bioprostheses on exercise hemodynamics in patients with a small aortic annulus. J Thorac Cardiovasc Surg. 2007;133:1234-41.

25. Blais C, Dumesnil JG, Baillot R, Simard S, Doyle D, Pibarot P. Impact of valve prosthesis-patient mismatch on short-term mortality after aortic valve replacement. Circulation. 2003;108:983-8

26. Mohty D, Dumesnil JG, Echahidi N, Mathieu P, Dagenais F, Voisine P, et al. Impact of prosthesis-patient mismatch on long-term survival after aortic valve replacement: influence of age, obesity, and left ventricular dysfunction. $J \mathrm{Am}$ Coll Cardiol. 2009;53:39-47.
27. Mohty-Echahidi D, Malouf JF, Girard SE, Schaff HV, Grill DE, EnriquezSarano ME, et al. Impact of prosthesis-patient mismatch on long-term survival in patients with small St Jude medical mechanical prostheses in the aortic position. Circulation. 2006;113:420-6.

28. Tasca G, Brunelli F, Cirillo M, Dallatomba M, Mhagna Z, Troise G, et al. Impact of valve prosthesis-patient mismatch on left ventricular mass regression following aortic valve replacement. Ann Thorac Surg. 2005;79:505-10.

29. Tasca G, Mhagna Z, Perotti S, Centurini PB, Sabatini T, Amaducci A, et al Impact of prosthesis-patient mismatch on cardiac events and midterm mortality after aortic valve replacement in patients with pure aortic stenosis. Circulation. 2006;113:570-6

30. Walther T, Rastan A, Falk V, Lehmann S, Garbade J, Funkat AK, et al. Patient prosthesis mismatch affects short- and long-term outcomes after aortic valve replacement. Eur J Cardiothorac Surg. 2006;30:15-9.

31. Blackstone EH, Cosgrove DM, Jamieson WRE, Birkmeyer NJ, Lemmer JH Jr Miller DC, et al. Prosthesis size and long-term survival after aortic valve replacement. J Thorac Cardiovasc Surg. 2003;126:783-96.

32. Cotoni DA, Palac RT, Dacey LJ, O'Rourke DJ. Defining patient-prosthesis mismatch and its effect on survival in patients with impaired ejection fraction. Ann Thorac Surg. 2011;91:692-9.

33. Flameng W, Meuris B, Herijgers P, Herregods MC. Prosthesis-patient mismatch is not clinically relevant in aortic valve replacement using the CarpentierEdwards Perimount valve. Ann Thorac Surg. 2006;82:530-6.

34. Howell NJ, Keogh BE, Barnet V, Bonser RS, Graham TR, Rooney SJ, et al Patient-prosthesis mismatch does not affect survival following aortic valve replacement. Eur J Cardiothorac Surg. 2006;30:10-4.

35. Monin JL, Monchi M, Kirsch MEW, Petit-Eisenmann H, Baleynaud S, Chauvel C, et al. Low-gradient aortic stenosis: impact of prosthesis-patient mismatch on survival. Eur Heart J. 2007;28:2620-6.

36. Hanayama N, Christakis GT, Mallidi HR, Joyner CD, Fremes SE, Morgan CD et al. Patient-prosthesis mismatch is rare after aortic valve replacement: valve size may be irrelevant. Ann Thorac Surg. 2002;73:1822-9.

37. Connolly HM, Oh JK, Schaff HV, Roger VL, Osborn SL, Hodge DO, et al. Severe aortic stenosis with low transvalvular gradient and severe left ventricular dysfunction: result of aortic valve replacement in 52 patients. Circulation. 2000; 101:1940-6.

38. Urso S, Sadaba R, Aldamiz-Echevarria G. Is patient-prosthesis mismatch an independent risk factor for early and mid-term overall mortality in adult patients undergoing aortic valve replacement? Int Cardiovasc Thorac Surg. 2009;9:510-8

39. David TE, Armstrong S, Maganti M. Hancock II bioprosthesis for aortic valve replacement: the gold standard of bioprosthetic valves durability? Ann Thorac Surg. 2010;90:775-81.

40. Jamieson WR, Janusz MT, MacNab J, Henderson C. Hemodynamic comparison of second- and third-generation stented bioprostheses in aortic valve replacement. Ann Thorac Surg. 2001;71:S282-4.

41. Suri RM, Zehr KJ, Sundt TM III, Dearani JA, Daly RC, Oh JK, et al. Left ventricular mass regression after porcine versus bovine aortic valve replacement: a randomized comparison. Ann Thorac Surg. 2009;88:1232-7.

42. Gerosa G, Tarzia V, Rizzoli G, Bottio T. Small aortic annulus: the hydrodynamic performances of 5 commercially available tissue valves. $J$ Thorac Cardiovasc Surg. 2006;131:1058-64.

43. Bottio T, Tarzia V, Rizzoli G, Gerosa G. The changing spectrum of bioprostheses hydrodynamic performance: considerations on in-vitro tests. Int Cardiovasc Thorac Surg. 2008;7:750-4.

\section{Discussion}

Dr Tirone E. David (Toronto, Ontario, Canada). Dr Suri and his colleagues from Mayo Clinic are to be commended for carrying out this prospective, randomized trial on early hemodynamic performance of 3 currently used bioprosthetic valves for AVR. Hemodynamic assessment of bioprosthetic valves a few days after implantation may not represent the final hemodynamic result of the bioprosthesis at 6 months or 1 year, and I hope Dr Suri will bring his patients back and tell us next year what happened to those gradients and the aortic valve sizes. Our specialty certainly needs more randomized controlled trials whenever possible, and choice 
of bioprosthetic valve for AVR is one of those areas. Dr Suri and colleagues' randomized trial showed that the mean gradient across the aortic valve was approximately $16 \mathrm{~mm} \mathrm{Hg}$ for Epic, $14 \mathrm{~mm} \mathrm{Hg}$ for Magna, and $16 \mathrm{~mm} \mathrm{Hg}$ for Mitroflow for the entire cohort of patients, and these values were statistically different with a $P$ value of .01. Similarly, the aortic valve areas were $1.86 \mathrm{~cm}^{2}$ for Epic, $2.05 \mathrm{~cm}^{2}$ for Magna, and $1.88 \mathrm{~cm}^{2}$ for Mitroflow, and the differences were again statistically significant. And so were the indexed orifice areas. My first question to you, Rakesh: Is there clinical relevance in these differences? In other words, do you believe that a mean gradient of $14 \mathrm{~mm} \mathrm{Hg}$ or $16 \mathrm{~mm} \mathrm{Hg}$ has any clinical consequence?

Dr Suri. Thank you, Dr David, for those comments. We do not currently believe that these small differences in transprosthetic gradient have clinical relevance during the early postoperative period. Cognizant of the fact that the perioperative changes in cardiac output caused by catecholamine elevations, anemia, and increased stroke volume early after surgery may temporarily elevate the transprosthetic gradient, we further analyzed the flow-independent measures of valve performance such as uncorrected AVA and AVAi. These comparisons also showed only very small differences among devices. It is interesting to note that there were slight variances in the outcome of the comparative analyses depending on whether data were stratified by implant size or actual annular size. Our European colleagues have written about these varying methods of analysis, stressing the importance of normalizing hemodynamic data by actual annular size to account for differences in commercial valve labeling. What is striking is that when we controlled for discrepancies in commercial size labeling, many of the differences among devices disappeared and the performance of the 3 valves over a range of directly measured universal annulus sizes was quite similar. Finally, our randomized cohorts are scheduled for clinical and echocardiographic followups at 1 year and 5 years. We are currently seeing patients for their 1 -year visit. We look forward to presenting these data in the future.

Dr David. Patient-prosthesis mismatch is really what we should try to avoid during AVR, particularly in patients who are physically very active or have impaired LV systolic function. Your trial showed that the average aortic valve index was around $1 \mathrm{~cm}^{2} / \mathrm{m}^{2}$ in all 3 groups of patients, and I commend you again for trying to implant the largest possible valve to avoid patientprosthesis mismatch. However, your surgeons had to patch enlarge the annulus in approximately $10 \%$ of your patients. Because the randomization was done after the patch enlargement, patch enlargement did not affect the outcomes, but it did bias the result on the hemodynamic performance of the valves. My next question to you is related to the fact that, although Magna showed the best hemodynamic performance, it also had the highest incidence of annular enlargement and also the highest incidence of mismatch. Although the differences were not statistically significant, they are, however, significant for the average surgeon who doesn't do this operation every day.

Dr Suri. Those are important considerations. To address your first point, when designing the trial protocol, we thought about surgical strategy in the following way. Assuming hemodynamic equipoise among devices, we wanted to understand the implications of placing each of the 3 valves in a given annular orifice.
We thus left it to the surgeon to perform an a priori assessment of whether aortic annular enlargement would first be required based on the estimated physiologic needs of the patient. What is reassuring is that all valves performed similarly well using this strategy, and the frequency of annular enlargement was comparable among groups. The specific question regarding who enlarges the aortic annulus is more complicated, and this study does not address that issue. These data indicate, however, that regardless of the valve type placed in a small aortic annulus, flow-dependant and -independent performance of the devices were indistinguishable statistically. Last, these data could also be interpreted to imply that in those with LV dysfunction, or who require maximization of postoperative AVA, annular enlargement is required. In other words, merely selecting a different prosthesis for a given annular dimension will not necessarily provide a significant increase in postoperative indexed orifice area. An interesting point to note in the data provided by the 3 companies themselves, which detail differences in dimensions of the 3 devices, are actual external valve size measurements. The Mitroflow valve has the smallest external diameter footprint, yet the valve performed very similarly to those with larger internal and external diameters. Finally, I will try to address your point on patch closure of the aortic root. To clarify, $4 \%$ of patients underwent patch enlargement of the aortic annulus and $10 \%$ had patch closure of the aortic root only. Despite the fact that the Magna valve is intermediate in external diameter and stent height between the 2 groups, the question is why surgeons slightly more frequently used a bovine pericardial patch to close the aortic root. Many of you will have your own suspicions regarding differences in stent characteristics; however, this study was not designed to draw definitive conclusions on that topic.

Dr David. Finally, if the hemodynamic performance of different porcine and pericardial valves is similar, surgeons should have to consider the durability of the bioprosthetic valve when matching the patient to the type of valve. One should not implant a valve only because it has excellent hemodynamic performance. I would like to thank The American Association for Thoracic Surgery for the privilege of discussing this paper.

Dr Suri. Thank you again, Dr David. That is a very important point. Dr David has recently published a seminal paper on longterm durability of biologic aortic valve prostheses and I encourage those of you who haven't read it to do so. The current study, Dr David, reflects the first step in our planned long-term follow-up of these patients. We hope to comment both on mid- and long-term durability of these devices in the future.

Dr Lawrence H. Cohn (Boston, Mass). I have a question about the patch enlargement. I have always been fascinated with this. The mean age of your group was 76 years of age and yet you patch enlarged $10 \%$, or 30 of the patients. Could you give us a feel for what kind of patient you are enlarging at this age group? A lot of these patients in my practice are elderly women-80 years old-and all they want to do is walk down the mall with their grandchildren, so we put in $19-\mathrm{mm}$ and $21-\mathrm{mm}$ valves quite frequently. I am would be curious as to what kind of patients were patched in this age group.

Dr Suri. That is a very interesting question, Dr Cohn. As you are aware in your own practice, we all do things slightly differently and thus have varying predispositions toward enlargement 
of the aortic annulus. Cardiac surgeons all seek to avoid severe patient-prosthesis mismatch; some use charts and other clinical judgment based on accrued surgical experience. Further, there is general agreement that severe mismatch is particularly problematic in those who are active or who have preoperative LV dysfunction, and thus at Mayo Clinic we would be particularly aggressive in enlarging the annulus of these patient subsets, as we did in $4 \%$ of the current study population. We are not suggesting that cardiac surgeons should be enlarging the annulus of all patients, particularly as you point out, in those who are frail and merely require amelioration of severe calcific AS to restore their quality of life with limited requirement for physical activity.

Dr Rohit Shahani (Poughkeepsie, NY). Thank you for a nice paper. When we talk about small sizes in the aorta, could you tell us in absolute numbers how many of the valves you put in were 19 ?

Dr Suri. Fourteen valves of size 19 were implanted overall: 3 Epic, 6 Magna, and 5 Mitroflow.

Dr Robert A. Dion (Genk, Belgium). Don't you think that, based on your findings, one still can make a decision about using a very small size? I have the impression that 1 of the 3 is doing better in gradients and in areas. Also, if one is confronted with a very small annulus and is being forced to insert $<$ size 21 , what would you do? Would you carry on enlarging the aortic root or would you go, for instance-what I am doing-for a full-root supra-annular stentless valve? Thank you.

Dr Suri. Thank you, Dr Dion. Those are good questions. The first point I will address is your last question, and I concur with the perspective of Dr Cohn on this; severe aortic stenosis patients with a normal ventricle who are small, elderly, frail, and have a normal ventricle can do very well with a no. 19 valve in the absence of severe mismatch. Notably, our data suggest that all valves studied in this randomized series performed equally well, with a low frequency of PPM in patients with a small aoric annulus. As is the case with most surgical decisions in our specialty, a thoughtful analysis of advantages and disadvantages as related to the specific clinical scenario in each patient is warranted. Additionally, we do not typically implant stentless valves or routinely enlarge the aortic annulus in small, frail, elderly patients unless there is predicted physiologic need based on individual clinical circumstances. The other question, as I understand it, is regarding the small hemodynamic differences noted between the combined commercial sizes nos. 19 and 21 groups. As I mentioned, longitudinal follow-up will be essential to track these 3 well-matched randomized subsets over time. Although one may speculate regarding potential late outcomes, we cannot currently conclude that there are clinically meaningful hemodynamic differences among any of the randomized valve groups during the early postoperative period.

Dr Guo-Wei He (Tianjin, China). I feel this is a very important study from the Mayo Clinic. Now, our practice pattern in China is different from your practice in the Mayo Clinic. In my own practice, up to $50 \%$ of the patients are still the result of rheumatic heart disease; another $50 \%$ are attributed to another etiology such as degeneration or infection. I have a question related to patients between the ages of 60 years and 65 years. In this situation, we may put either a bioprosthesis or a mechanical valve in. I would like to know, in the Mayo Clinic experience, as far as the hemodynamic effect is concerned, in this age group, which valve prosthesis would you use? A bioprosthesis or a mechanical valve?

Dr Suri. This is a very interesting question. There are 2 factors we discuss we consider when helping patients decide between mechanical versus biological valve substitutes in the so-called gray zone. The first, as you said, is hemodynamic performance. In the current era with novel, third-generation biologic devices, the hemodynamic differences between mechanical and biologic devices are not large, and thus this seldom is the most influential factor in determining prosthesis choice. The second point is an important and less well understood concept - the late potential survival difference between valve types. There is a growing body of evidence to suggest that there may be a long-term survival advantage associated with implantation of a mechanical versus a biologic aortic valve in risk-matched middle-aged patients. Of course, the opposing argument would be that the quality-of-life implications of oral anticoagulants are more influential on prosthesis choice. However, that debate is beyond the scope of the discussion today. We currently have a manuscript submitted that addresses the late prognostic implications of mechanical versus biologic aortic valve replacement and we hopefully will have more to share on the topic in the near future. Ultimately, patients at Mayo Clinic undergoing preoperative assessment for valve replacement are thoroughly informed of indications, risks, benefits, and alternatives before selecting an appropriate prosthetic valve substitute.

Dr Joseph Ladowski (Ft. Wayne, Ind). Dr Suri, not an elegant question, but a practical one. If you yourself needed one of these valves tomorrow, which one do you want?

Dr Suri. For the sake of maintaining equipoise as the principal investigator of this study, and as the data have confirmed is warranted at the current time in light of small differences between the valves studied in this trial, I am going to politely defer that question. I thank The American Association for Thoracic Surgery for the opportunity to present our data today. 
APPENDIX 1. Dismissal echocardiogram data comparison stratified by implant size

\begin{tabular}{|c|c|c|c|c|c|}
\hline Implant size & Dismissal echocardiogram & Epic $(n=29)$ & $\operatorname{Magna}(\mathbf{n}=35)$ & Mitroflow $(\mathbf{n}=36)$ & $P$ value \\
\hline \multirow[t]{4}{*}{ Nos. 19 and $21(\mathrm{n}=100)$} & & $\mathrm{n}=29$ & $\mathrm{n}=35$ & $\mathrm{n}=36$ & \\
\hline & Mean gradient, $\mathrm{mm} \mathrm{Hg}$ & $17.11 \pm 6.29(15.50)$ & $16.62 \pm 6.35(16.00)$ & $16.66 \pm 6.12(16.00)$ & .945 \\
\hline & Aortic valve area, $\mathrm{cm}^{2}$ & $1.55 \pm 0.29(1.56)$ & $1.61 \pm 0.34(1.66)$ & $1.59 \pm 0.40(1.59)$ & .799 \\
\hline & Aortic valve area index, $\mathrm{cm}^{2} / \mathrm{m}^{2}$ & $0.86 \pm 0.18(0.86)$ & $0.92 \pm 0.21(0.92)$ & $0.92 \pm 0.27(0.89)$ & .581 \\
\hline \multirow[t]{4}{*}{ No. $23(\mathrm{n}=94)$} & & $\mathrm{n}=33$ & $\mathrm{n}=33$ & $\mathrm{n}=30$ & \\
\hline & Mean gradient, $\mathrm{mm} \mathrm{Hg}$ & $16.26 \pm 5.57(18.00)$ & $14.16 \pm 4.88(14.00)$ & $17.97 \pm 6.18(18.00)$ & $.032 *$ \\
\hline & Aortic valve area, $\mathrm{cm}^{2}$ & $1.79 \pm 0.37(1.79)$ & $2.02 \pm 0.32(1.96)$ & $1.80 \pm 0.39(1.81)$ & $.025 \dagger$ \\
\hline & Aortic valve area index, $\mathrm{cm}^{2} / \mathrm{m}^{2}$ & $0.91 \pm 0.23(0.87)$ & $1.04 \pm 0.21(0.96)$ & $0.90 \pm 0.20(0.90)$ & $.028 \ddagger$ \\
\hline \multirow[t]{4}{*}{ Nos. 25 and $27(n=106)$} & & $\mathrm{n}=37$ & $\mathrm{n}=34$ & $\mathrm{n}=35$ & \\
\hline & Mean gradient, $\mathrm{mm} \mathrm{Hg}$ & $16.24 \pm 7.29(16.00)$ & $11.91 \pm 3.98(11.00)$ & $14.54 \pm 5.67(13.00)$ & $.009 \S$ \\
\hline & Aortic valve area, $\mathrm{cm}^{2}$ & $2.17 \pm 0.47(2.18)$ & $2.50 \pm 0.49(2.45)$ & $2.25 \pm 0.52(2.12)$ & $.019 \|$ \\
\hline & Aortic valve area index, $\mathrm{cm}^{2} / \mathrm{m}^{2}$ & $1.05 \pm 0.28(1.02)$ & $1.18 \pm 0.26(1.09)$ & $1.08 \pm 0.28(1.05)$ & .158 \\
\hline
\end{tabular}

Echocardiogram variables are summarized as mean \pm (median). *Epic vs Magna, $P=.290$; Epic vs Mitroflow, $P=.461$; Magna vs Mitroflow, $P=.024$. †Epic vs Magna, $P=.042$; Epic vs Mitroflow, $P=.989$; Magna vs Mitroflow, $P=.057$. $\ddagger$ Epic vs Magna, $P=.068$; Epic vs Mitroflow, $P=.986$; Magna vs Mitroflow, $P=.044$. $\S$ Epic vs Magna, $P=.007$; Epic vs Mitroflow, $P=.437$; Magna vs Mitroflow, $P=.154$. $\|$ Epic vs Magna, $P=.019$; Epic vs Mitroflow, $P=.770$; Magna vs Mitroflow, $P=.102$.

APPENDIX 2. Dismissal echocardiogram data comparison stratified by universal size

\begin{tabular}{|c|c|c|c|c|c|}
\hline Universal size, $\mathbf{m m}$ & Dismissal echocardiogram & Epic & Magna & Mitroflow & $P$ value \\
\hline \multirow[t]{4}{*}{$<23 \mathrm{~mm}(\mathrm{n}=77)$} & & $\mathrm{n}=23$ & $\mathrm{n}=24$ & $\mathrm{n}=30$ & \\
\hline & Mean gradient, $\mathrm{mm} \mathrm{Hg}$ & $16.50 \pm 6.01(14.50)$ & $17.13 \pm 6.74(16.00)$ & $16.41 \pm 6.72(16.00)$ & .917 \\
\hline & Aortic valve area, $\mathrm{cm}^{2}$ & $1.55 \pm 0.32(1.57)$ & $1.62 \pm 0.39(1.67)$ & $1.68 \pm 0.43(1.63)$ & .547 \\
\hline & Aortic valve area index, $\mathrm{cm}^{2} / \mathrm{m}^{2}$ & $0.86 \pm 0.19(0.86)$ & $0.93 \pm 0.25(0.92)$ & $0.96 \pm 0.28(0.94)$ & .366 \\
\hline \multirow[t]{4}{*}{$23 \mathrm{~mm}(\mathrm{n}=95)$} & & $\mathrm{n}=32$ & $\mathrm{n}=28$ & $\mathrm{n}=35$ & \\
\hline & Mean gradient, $\mathrm{mm} \mathrm{Hg}$ & $16.87 \pm 6.10(18.00)$ & $14.00 \pm 4.15(14.00)$ & $16.74 \pm 5.90(16.00)$ & .084 \\
\hline & Aortic valve area, $\mathrm{cm}^{2}$ & $1.70 \pm 0.34(1.66)$ & $1.91 \pm 0.33(1.87)$ & $1.78 \pm 0.47(1.65)$ & .138 \\
\hline & Aortic valve area index, $\mathrm{cm}^{2} / \mathrm{m}^{2}$ & $0.88 \pm 0.20(0.85)$ & $1.02 \pm 0.18(0.97)$ & $0.91 \pm 0.24(0.87)$ & $.040 *$ \\
\hline \multirow[t]{4}{*}{$>23 \mathrm{~mm}(\mathrm{n}=128)$} & & $\mathrm{n}=44$ & $\mathrm{n}=48$ & $\mathrm{n}=36$ & \\
\hline & Mean gradient, $\mathrm{mm} \mathrm{Hg}$ & $16.25 \pm 6.95(16.00)$ & $12.98 \pm 5.07(12.00)$ & $15.81 \pm 5.86(14.50)$ & $.021 \dagger$ \\
\hline & Aortic valve area, $\mathrm{cm}^{2}$ & $2.12 \pm 0.47(2.18)$ & $2.34 \pm 0.54(2.17)$ & $2.14 \pm 0.53(2.05)$ & .103 \\
\hline & Aortic valve area index, $\mathrm{cm}^{2} / \mathrm{m}^{2}$ & $1.04 \pm 0.28(1.00)$ & $1.12 \pm 0.27(1.07)$ & $1.03 \pm 0.27(1.01)$ & .275 \\
\hline
\end{tabular}

Echocardiogram variables are summarized as mean \pm standard deviation (median). *Epic vs Magna, $P=.045$; Epic vs Mitroflow, $P=.886$; Magna vs Mitroflow, $P=.106$. $\dagger$ Epic vs Magna, $P=.027$; Epic vs Mitroflow, $P=.942$; Magna vs Mitroflow, $P=.086$.

APPENDIX 3. Dismissal echocardiogram data comparison stratified by LVOT size

\begin{tabular}{|c|c|c|c|c|c|}
\hline LVOT size & Dismissal echocardiogram & Epic & Magna & Mitroflow & $P$ value \\
\hline \multirow[t]{4}{*}{$\leq 21(\mathrm{n}=85)$} & & $\mathrm{n}=23$ & $\mathrm{n}=30$ & $\mathrm{n}=32$ & \\
\hline & Mean gradient, $\mathrm{mm} \mathrm{Hg}$ & $18.09 \pm 8.87(15.00)$ & $15.62 \pm 6.66(14.00)$ & $15.32 \pm 5.96(15.00)$ & .332 \\
\hline & Aortic valve area, $\mathrm{cm}^{2}$ & $1.59 \pm 0.27(1.58)$ & $1.69 \pm 0.37(1.76)$ & $1.84 \pm 0.54(1.67)$ & .116 \\
\hline & Aortic valve area index, $\mathrm{cm}^{2} / \mathrm{m}^{2}$ & $0.88 \pm 0.17(0.87)$ & $0.94 \pm 0.20(0.93)$ & $1.02 \pm 0.29(1.01)$ & .099 \\
\hline \multirow[t]{4}{*}{$22-23(n=29)$} & & $\mathrm{n}=44$ & $\mathrm{n}=41$ & $\mathrm{n}=44$ & \\
\hline & Mean gradient, $\mathrm{mm} \mathrm{Hg}$ & $16.43 \pm 5.38(16.50)$ & $14.88 \pm 5.56(16.00)$ & $17.09 \pm 6.43(17.50)$ & .205 \\
\hline & Aortic valve area, $\mathrm{cm}^{2}$ & $1.88 \pm 0.47(1.86)$ & $2.06 \pm 0.46(2.03)$ & $1.78 \pm 0.47(1.63)$ & $.029 *$ \\
\hline & Aortic valve area index, $\mathrm{cm}^{2} / \mathrm{m}^{2}$ & $0.96 \pm 0.27(0.91)$ & $1.06 \pm 0.26(0.98)$ & $0.90 \pm 0.24(0.88)$ & $.017 \dagger$ \\
\hline \multirow[t]{4}{*}{$>23(\mathrm{n}=84)$} & & $\mathrm{n}=31$ & $\mathrm{n}=28$ & $\mathrm{n}=25$ & \\
\hline & Mean gradient, $\mathrm{mm} \mathrm{Hg}$ & $15.48 \pm 5.68(16.00)$ & $11.82 \pm 2.89(11.00)$ & $16.16 \pm 5.66(16.00)$ & $.003 \ddagger$ \\
\hline & Aortic valve area, $\mathrm{cm}^{2}$ & $2.03 \pm 0.50(1.96)$ & $2.40 \pm 0.55(2.30)$ & $2.10 \pm 0.52(2.02)$ & $.027 \S$ \\
\hline & Aortic valve area index, $\mathrm{cm}^{2} / \mathrm{m}^{2}$ & $0.99 \pm 0.27(0.93)$ & $1.13 \pm 0.26(1.07)$ & $1.02 \pm 0.27(1.01)$ & .161 \\
\hline
\end{tabular}

Echocardiogram variables are summarized as mean \pm standard deviation (median). LVOT, Left ventricular outflow tract. *Epic vs Magna, $P=.222 ;$ Epic vs Mitroflow, $P=.571 ;$ Magna vs Mitroflow, $P=.022$. †Epic vs Magna, $P=.163$; Epic vs Mitroflow, $P=.558$; Magna vs Mitroflow, $P=.013$. $\ddagger$ Epic vs Magna, $P=.015$; Epic vs Mitroflow, $P=.866$; Magna vs Mitroflow, $P=.006$. $\S$ Epic vs Magna, $P=.029$; Epic vs Mitroflow, $P=.863$; Magna vs Mitroflow, $P=.110$. 